\title{
Understanding Climate Adaptation Cultures in Global Context: Proposal for an Explanatory Framework
}

\author{
Thorsten Heimann ${ }^{1}$ and Bishawjit Mallick ${ }^{2,3,4, *}$ \\ 1 Department "Dynamics of Communication, Knowledge and Spatial Development", \\ Leibniz Institute for Research on Society and Space (IRS), Erkner 15537, Germany; \\ thorsten.heimann@leibniz-irs.de \\ 2 Department of Political Science, Vanderbilt University, Nashville, TN 37203, USA \\ 3 International Migration Institute, The University of Oxford, Oxford OX1 3TB, UK \\ 4 Institute of Regional Science (IfR), Karlsruhe Institute of Technology (KIT), Karlsruhe 76131, Germany \\ * Correspondence: bishawjit_mallick@biari.brown.edu; Tel.: +49-721-608-42383
}

Academic Editor: Yang Zhang

Received: 30 September 2016; Accepted: 2 December 2016; Published: 9 December 2016

\begin{abstract}
This paper aims at enhancing the previously formulated culture-theoretical explanation of risk-related perception and action with ecological and institutional connectedness. This is needed for global comparison of adaptation cultures as well as transferability of local knowledge. Differences in climate-related patterns of knowledge will therefore be explained by common patterns of socially shared knowledge in relation to ecological and institutional transformation. This will be done by combining a cultural-knowledge approach with different social-ecological and institutional contexts. Changes in knowledge development as well as in adaptation practices will be described by state-and-transition. The proposed approach combines the culture-theoretical explanation of Values-Beliefs-Identities (VBI) and socio-ecological as well as institutional approach of the state-and-transition model.
\end{abstract}

Keywords: adaptation culture; Value-Belief-Identities (VBI); state-and-transition; European coastal areas; Bangladesh; climate knowledge

\section{Introduction}

Cultures of climate-change adaptation differ worldwide. These can be understood as differences in perception of vulnerability as well as in preferred practices for creating resilience. The knowledge oriented "culture as relational space" approach [1] describes the climate-cultural constellations. Furthermore, a knowledge-oriented perspective explains diverse adaptation cultures via different forms of background knowledge being internalized by individuals and groups [1]. Nevertheless, factors to explain differences in perceiving and handling climate change besides "shared knowledge" remain "blind spots". To explain different perceptions and climate-adaptation practices for societies of stronger difference, like the Global South and the Global North, it is of high importance that aspects besides knowledge are considered. For example, Mallick [2] explains the adaptation processes in the context of concrete disaster events. His study refers to environmental conditions, economic resources, and social capital (networks and connections) having relevance for local adaptation practices. His study refers to the constellations of environmental sociology as well as the local political-economic approach. Environmental sociology has aimed at including environmental factors in its explanation [3-6] of how social behaviors form the environmental outcome, as well as how environmental context influences action. Political Economy of climate change considers the local socio-political constraints, such as issues related to power, inequality, and governance [7-9], whereas rational-choice theory [10,11] 
considers costs and benefits to be the determinants of the individual choices of adaptation strategies [7]. Social-ecology includes the institutional and legislative context of climate change adaptation $[8,9,12,13]$ and lacks the integration of cultural knowledge.

Nevertheless, the cultural differences in adaptation practices are not well considered in those approaches and therefore, so called "best-practice" adaptation strategies of the Global North meet restrictions to be implemented at the Global South, or vice versa. Therefore, the transferability of adaptation practices as well as knowledge construction is not reflected by any of these approaches. For global comparison and transferability, or even stand-alone research on adaptation culture, it is necessary to create a theoretical framework that explains the perception and practices of climate adaptation combining cultural, ecological, and institutional contexts. Until today there is no such explanatory framework available.

Based on two empirical studies, this paper therefore proposes to develop an enhanced integrated framework for the explanation of cultural differences in adaptation. In those studies, the differences in adaptation cultures have been observed for different regional contexts: one for the Global North, especially European coastal areas, and another for the Global South, in particular the coastal areas of Bangladesh. The studies deliver an impulse for improvement of their theoretical frameworks for the explanation of cultural differences in adaptation. The next section summarizes both empirical and theoretical approaches, and discusses the importance of further improvement of the employed models.

\section{Insights from Empirical Studies}

\subsection{Study 1: European Coastal Areas}

The empirical example of European coastal areas is based on the research of Heimann [1] Firstly, a theoretical and empirical approach for describing climate-cultural differences has been developed. Secondly, a culture-oriented explanatory framework was implemented using different forms of background knowledge to explain differences in perceiving and handling climate change, namely value orientations, ecological beliefs, and identities (VBI-Model, [1]). The following section summarizes both approaches in the context of empirical evidence from European coastal areas and claims the importance of a holistic approach that captures the changes in climate-change knowledge development in local socio-ecological and institutional contexts and its impacts on adaptation practices.

\subsubsection{Theoretical Approach: Climate Cultures and Values-Beliefs-Identities Explanatory-Framework}

Culture is considered as "shared knowledge" [14,15] between individuals and/or groups. In recent knowledge-oriented social-science research the term "knowledge" implies a broad understanding, comprising shared cognitive and normative framings (e.g., shared problem framings for climate change, general values, beliefs, and identities) as well as shared practices at the level of action [16].

The study focusses on recent debates on cultural globalization, in which the congruence of place and culture is increasingly doubted due to the recent increase of global communication and knowledge exchange. As climate-change related knowledge and practices might be shared worldwide, the first question is how climate cultures are constellated. Here, as cultures are constituted by shared knowledge, cultures are seen as arranging themselves along certain aspects, in this case climate-change related knowledge and practice. To be able to determine the constellation of recent climate cultures the study suggests exploring "culture as relational space" [1] (p.49). Here, the term "space" is used as agents sharing certain kinds of knowledge that can be seen as more or less distant from each other. Consequently "climate cultures" are similar forms of knowledge and practices being shared by different agents and groups.

Different sub-forms of climate-change related knowledge can be shared, and the study therefore differentiates between shared knowledge of vulnerability and shared knowledge of resilience. Shared knowledge of vulnerability refers to possible problems and opportunities related to climate change which are seen by different agents. Shared knowledge of resilience implies practices to mitigate or to adapt to 
climate change (e.g., flood-related practices commonly shared by local households living close to river regions in Bangladesh and Germany) [1].

It was questioned, furthermore, how different climate cultures can be explained from a culture-theoretical point of view. Therefore, a culture-oriented explanatory framework for climate change adaptation was suggested and tested with empirical evidence [1]. From a social-constructivist point of view, it was argued that different forms of knowledge which are internalized in the past restrict the scope of future interpretation and action $[1,15,17]$ (e.g., an internalized belief that nature is strongly fragile allows only specific views of climate change as a problem). Consequently, systematic interrelations between different forms of knowledge emerge as "orders of knowledge" [18,19].

To explore these orders, this study focuses on social-science debates in which explanations for environment- and climate-change related behavior are suggested by common forms of knowledge, namely values, beliefs, and identities [20-26] (Figure 1). Most climate-change related studies use only particular values, beliefs, and identities to explain differences. Nevertheless, as they are all discussed as relevant factors, an integrated conceptual framework has been implied. It considers all three basic components (values, beliefs, and identities) in order to explain different climate-adaptation cultures [1] (p.104).

- Values: Values are "conception(s, TH) ( . . ) of the desirable" [27]. The "values-based approach" [20] of climate adaptation suggests that values are of relevance for explaining climate-cultural differences in climate-change perception and adaption. In adaptation discourse, different conceptions are considered ranging from conservation, openness to change, safety, altruism [20,28,29], postmaterialism, [30,31] to individual vs. community orientation [32-34]. The study makes use of the value-approach of Shalom Schwartz [29], as this covers many of the concepts that are discussed for climate adaptation (e.g., openness to change, conservation, self-orientation, and altruism).

- Beliefs: Individual and collective ideas about the state of world [35] are also considered for explaining differences in climate adaptation. The role, especially of ecological worldviews, was discussed, in particular the ideas concerning human environment relationships [22,34,36-38]. The study makes use of the Human Exceptionalism vs. New Ecological Paradigm [5,6]. The Human Exceptionalism Paradigm (HEP) implies an anthropocentric worldview, where humans hold a superior position in nature. The New Ecological Paradigm (NEP) denies this perspective and claims that humans are not exceptional vis-à-vis other creatures [6].

- Identities: In climate-change related research attention has been focused especially on places in which identity concepts are discussed $[25,26,39,40]$. The core idea is that places can be of relevance for the self-definition of individuals and groups. As climate adaptation is related to changing place conditions or even losing land to water, place-related identities can explain, for example, why retreat or accommodation strategies are preferred or not for flood prevention. Consequently, the study uses the concept of place identity to explain climate-change related perception and action differences.

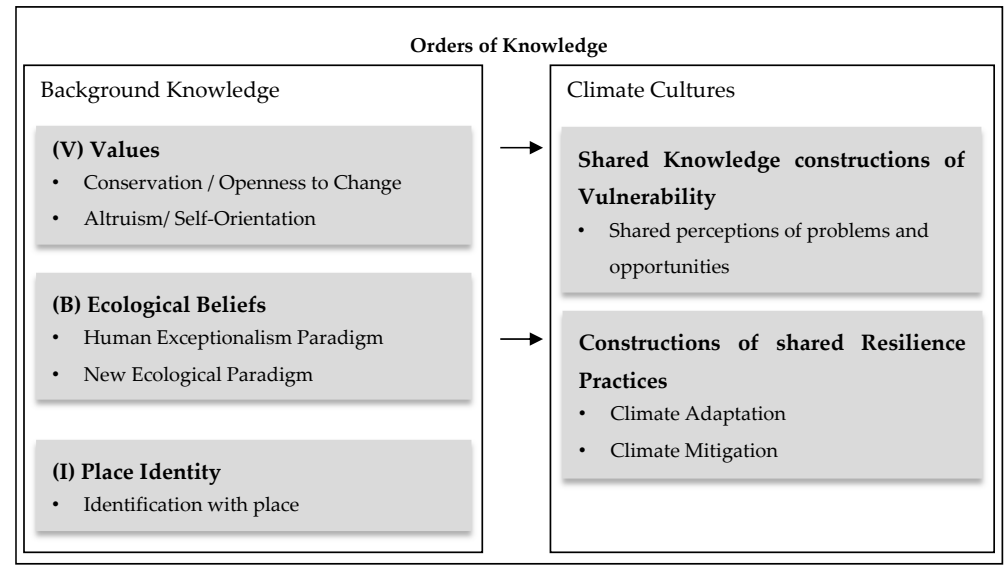

Figure 1. Values-Beliefs-Identities approach, adopted from Heimann [1]. 


\subsubsection{Methods}

The empirical study focuses on planners responsible for spatial planning for coastal communities in Germany, the Netherlands, Denmark, and Poland. An online survey was conducted in 2012, reaching a net sample of 830 planners working in the fields of politics, administration, civil society, and economy [1].

\subsubsection{Results: Climate Adaptation Cultures and Explanations for Differences}

The "culture as relational space" approach allows for the description of climate-adaptation cultures related to flooding, which emerge throughout all the European coastal areas of interest. Climate-cultural constellations are described by analyzing how similar forms of climate-change related knowledge and practices are shared. Here, cluster analyses are used to find groups sharing similar forms of knowledge. Thus, similar "cultures of climate adaptation" were found. The results show that flood management is divided into four cultures of adaptation: Protectionists, Renaturators, Universalists, and Minimalists. Universalists (39\%) are confirmed by a strategy mixing protection, retreat, and accommodation strategies. Renaturators (36\%) aim to concentrate on making "room for water" by retreating from land use and renaturation. Protectionists $(10 \%)$ prefer only technical protection strategies like the enhancement of dykes and other constructions. Minimalists (9\%) rarely declare any need for climate adaptation.

To be able to capture space-related climate-cultural constellations, the study explores different factors discriminating climate cultures, for example, regional or national background. The result reached is that the place of origin of the interviewees has an influential role on the constellation of these four climate cultures. At the national level, certain differences are observed: Renaturators emerge significantly more frequently in Germany (43\%) and Denmark (43\%), while Universalists form bigger groups in the Netherlands (51\%) and Poland (52\%). Furthermore, while technical protectors build smaller groups in Germany, the Netherlands, and Denmark, they are more frequent in Poland $(23 \%)$.

How the background knowledge of interviewees affects their affiliation to climate-adaptation cultures is determined by the Values-Beliefs-Identities approach. Logistic regression analyses explain different group affiliations. It can be shown that, for example, security- and conservation-value orientations lead to a higher probability of being Protectionist, while at the same time openness to change influences group affiliations towards being Universalist. The "New Ecological Paradigm" (NEP) in contrast to the "Human Exceptionalism Paradigm" (HEP) [4,5] was used to explain the influence of ecological beliefs. The results show that a change from HEP to NEP influences the probability of being Protectionist in favor of being a Renaturator. This means that a change from HEP to NEP can refer to a change from "struggle against water" [41] to "living with water" [42], whereas identification with certain areas does not influence group affiliations.

\subsubsection{Outlook: Blind Spots of the Knowledge-Oriented Approach}

Firstly, the knowledge-oriented "culture as relational space" approach can be used to provide the description of climate-cultural constellations worldwide and to test their discriminations by local affiliations. Secondly, a knowledge-oriented perspective can explain different adaptation cultures through the different forms of background knowledge internalized by respondents (in this case, different values, beliefs, and identities).

Nevertheless, factors other than "shared knowledge" remain "blind spots" in explaining differences in perceiving and handling climate change.

The study shows that adaptation cultures can change in the course of time with regard to certain events. This was, for example, the case in Denmark, which was more strongly affected by oil crises in the 1970s compared to Germany. There is much evidence that this has led to stronger ecological worldviews in Denmark [1]. Other examples are the Netherlands and Germany, where a change from the dominant HEP to NEP worldviews might have changed the flood-adaptation cultures from a higher 
focus on protection towards accommodation and retreat strategies [1]. Such changes in knowledge development as well as adaptation practices cannot be explained by a single VBI model. Therefore, a holistic approach is needed that explains the chronological development of climate knowledge in societies. The next section provides information on how changes in societies have taken place following disastrous events by employing a "state-and-transition" model [2]. In this study, the change of climate culture connected to natural hazard events shows that ecological and institutional constellations are also important factors for explaining different adaptation cultures.

\subsection{Study 2: Bangladesh Coastal Areas}

The empirical example of Bangladesh is based on Mallick's analysis of social relationships for vulnerability-oriented spatial planning in coastal areas of Bangladesh [2]. The study reveals how local coastal communities in Bangladesh perceive a cyclone, how they react and how they adapt to aftermath livelihood challenges. These questions are based on the process analysis of resilience to a hazardous event. The following sections briefly describe this study.

\subsubsection{Theoretical Framework: "State-and-transition" Model as Analytical Approach}

At-risk people are often misunderstood as "traditionally fatalist" because of answers given, such as "praying to Allah", when they are asked about their response to any hazard. Accordingly, for those vulnerable people, adaptive capacity is a bottom-up choice, and the design of adaptation strategies and its delivery and regulation are top-down. For example, Islam and Atkins [43] explain how the villagers of southern Bangladesh are using their indigenous knowledge of floating-bed cultivation skills in a water-logged environment. In such contexts, peoples' resilience includes local self-help activities, aided by kinship or local social networks, or traditional community structures with social harmony, and can be termed "social capital". Being resilient to a disaster therefore depends on internal capacities and external supports [44,45]. In human geography, climate-change adaptation clarifies how people adapt, and the adaptation is understood based on the given vulnerability and resilience of the systems. Vulnerability to a disaster can therefore be defined by pre-event capabilities (including both internal and external resources and abilities) and resilience can be understood both as a process and as an outcome after a disaster. The outcome-oriented resilience framework [46] entails the final outcome, for example, a "bounce back to the status quo", whereas the process-oriented frameworks refers to resilience as a dynamic concept. The most noteworthy model of process-based resilience is the Disaster Resilience of Place (DROP) model proposed by Cutter et al. [47]. The DROP model describes the pre-event status of a group or community or society as the form of vulnerability, and the post-event process captures the dynamic notion of resilience by accounting for coping, rehabilitation, and adaptation. Forgette and Boening's [48] " 4 Rs" model measures resilience by assessing household capacity in terms of risk recognition, resistance, redundancy, and rapidity. However, there is currently no single model that covers the full spectrum of all of the scientifically accepted aspects of disaster resilience. For this reason, this study employed the "state-and-transition" model, first developed by Westoby et al. [49], as it accommodates a broader spectrum of resilience dynamics [50]. Here, the model is modified to make it useful for understanding socio-economic resilience to natural disasters, and assumes that exogenous environmental shocks (e.g., cyclones or floods) may invoke a level of devastation that exceeds a system's capacity to maintain the characteristics of the pre-event steady state, triggering an irreversible transition as the system crosses the threshold and moves from one steady state to another. Here, a system can be interpreted as an individual or a community. Previous research in the social-vulnerability literature has revealed the links between poverty, sensitivity, exposure, response, and adaptive capacity (i.e., the poor are more vulnerable (according to both narrow and broad definitions of vulnerability) and less prepared) [51,52]. Hence, for this research, the state-and-transition process was divided into five phases by employing a disaster-management cycle: pre-event steady situation, coping, recovery and rehabilitation, adaptation, and post-event steady situation 
(Figure 2). The following section briefs the empirical tools that were adopted for collecting information in the context of this "state-and-transition" model.

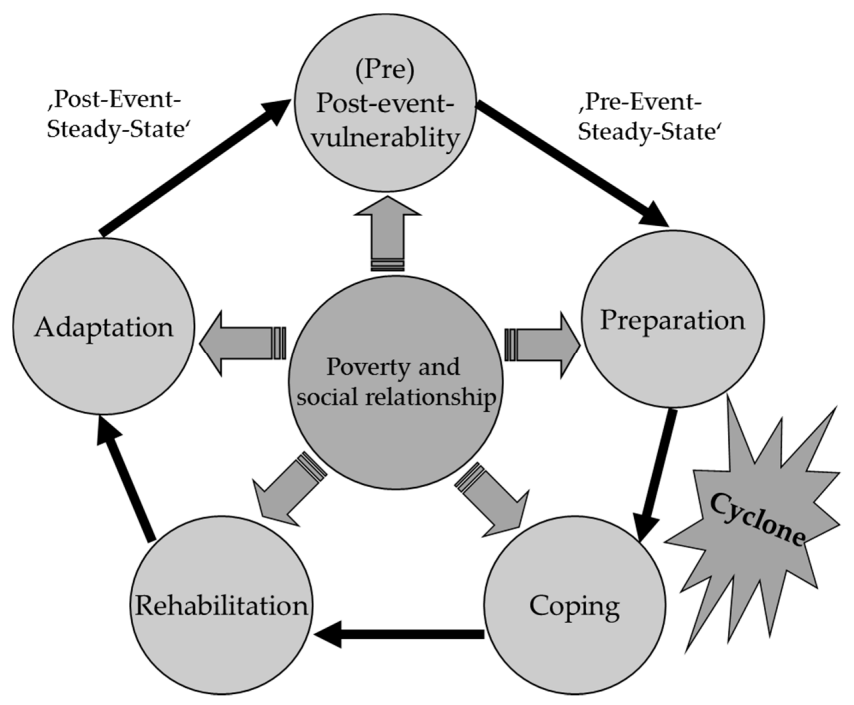

Figure 2. State-and-Transition Model in disaster resilience, adopted from Mallick [2].

\subsubsection{Methods}

This study focuses on cyclone Sidr from 2007 and cyclone Aila from 2009. Both of these cyclones hit southwest coastal Bangladesh. To capture the total spectrum of these cyclones, a mixed-method field survey was conducted which included household interviews (using a structured questionnaire), group discussion, and experts interview (using question lists). A total of 1555 heads of household were interviewed, as were experts and activists involved in post-cyclone rehabilitation and recovery management. The field-study questions investigate the communication rationalities of cyclone-affected people pre-, during, and post-cyclone situation, which, in general, later on describes the social spectrum of coping strategies and adaptation practices.

\subsubsection{Results: Socio-Ecological and Institutional Relevance for Adaptation}

The results show that socio-ecological environments and institutions play vital roles in every step of cyclone disaster management. In the study, the pre-event steady state denotes that the local environment and social capital provide support for decision making during a cyclone. For example, the elevation of interviewed households' dwellings and the available refugee centers influence the decision of taking refugees during a cyclone. Institutional perspective raises the availability of community-level support for taking refugees during a cyclone. In Bangladesh, cyclone shelters are an important institutional infrastructure of refugee management and means of coping with cyclones. The government of Bangladesh aims to provide access to cyclone shelters for everybody living in cyclone-prone coastal areas [2]. Employing geographic information system (GIS)-based spatial analysis, the study found that locally and socially powerful people are located close to cyclone shelters, but the masses of poor people are positioned far away and therefore have less access to cyclone shelter during emergencies. This is because local planning practices are dominated by informal governance, which thus influence adaptation practices as well.

Similarly, preparation depends on institutionalization of early warning systems and also on individual perception of an event. The study revealed that almost two-third of the respondents received the early warning message, whereas only 30 percent of them took action to prepare.

In the next stage, the study identifies the refugee places or institutions. The group discussions and household surveys gave information on this question and it was found that only a minority of inhabitants sought refuge in the cyclone shelters, although they offered sufficient intake capacity. 
The results of a principal component analysis offer justification for why a minority of inhabitants used the shelters: the reception of the early warning plays the most important role, followed by the individual household's preparedness. The state of the respondents' dwelling also certainly plays a key role in their decision-taking. Possibly due to cultural reasons, women take refuge in cyclone shelters less often than men [53].

Social capital, for example, connectedness with local NGOs, local government, or politicians, has a strong influence on rebuilding and rehabilitation programs. In the rehabilitation phase, measures of emergency assistance were unevenly distributed. Political and social power as well as geographical location plays a major role in rehabilitation; for example, the peripheral regions hardly benefit from any emergency assistance [54]. This serves as an instrument to preserve the local disparity of power, and possibly also to increase one's own influence [55]. The nature and pattern of adopted livelihood strategies depend mainly on the changes in the local political economy, particularly the available economic resources and societal supports through institution and politics. The study observed that the respondents sold their crops, cattle, or jewelry, changed their occupation, borrowed money, and also migrated for alternative income $[55,56]$.

\subsubsection{Outlook: Blind Spots of "Socio-Ecological and Institutional" Approach}

The adopted "state-and-transition" model covers how environmental, socio-economic, and institutional context can influence the handling of disaster risk. The socio-economic conditions of the affected people have influence at every stage of the state-and-transition process after a cyclone, and thus show in the case of Bangladesh that households with higher incomes have higher quality of adaptability to cyclones. It also observed that relief efforts are exploited by those in power. This means that disaster-related action highly depends on economic ability and institutional affiliation.

In particular, the adaptation culture in terms of local knowledge development has not been adequately explained by the study. A cultural-knowledge based approach would help to improve the effectiveness of disaster management and to identify and to prioritize factual and efficient measures for the adequate reduction of risks by the local communities and authorities.

In general, a close correlation in the context of transferability between the Global South and Global North countries in terms of adaptation strategies is absent. Public policies must be geared to local peculiarities, rather than to call for technical means of prevention from foreign experts [57].

Hence, all the available resilience frameworks (outcome or process) and even this modified "state-and-transition" model do not explain the climate-knowledge development process, which has been interpreted in Heimann [1] as the construction of vulnerability knowledge and construction of resilience practices. This recognizes the demand for an integration of social practices, culture, and local perceptions and knowledge into socio-ecological and institutional contexts in explaining adaptation culture on a global scale.

\section{Importance of Integration}

Both studies raise the combination of cultural knowledge with socio-ecological, economical, and institutional contexts, so that the combined framework can better explain adaptation cultures. For example, the Bangladesh study covers the economic conditions and environmental factors that derive the spectrum of disaster management practices in the country, but does not cover the cultural aspects of vulnerability constructions. The development of shared knowledge and the social construction of vulnerability and resilience remain blind spots in this case. The influences of background knowledge on adaptation culture therefore need to be taken into consideration in the case of Bangladesh. The European case study shows that background knowledge plays a vital role in adaptation, but does not include ecological, environmental, and socio-economic factors. Both might have different influences on perception and adaptation practices, as is described by the Bangladesh study. Therefore, it is assumed that influential factors might differ in effect size according to locality (e.g., Global South and Global North). 


\section{Proposal for an Enhanced Explanatory Framework of "Climate Adaptation Cultures"}

Both studies have shown promise in theoretical progress through empirical evidence. Jointly, they claim the importance of an innovative model that captures the spectrum of both "state-and-transition" and "VBI" models. Therefore, an explanatory model is proposed in this paper and presented in Figure 3.

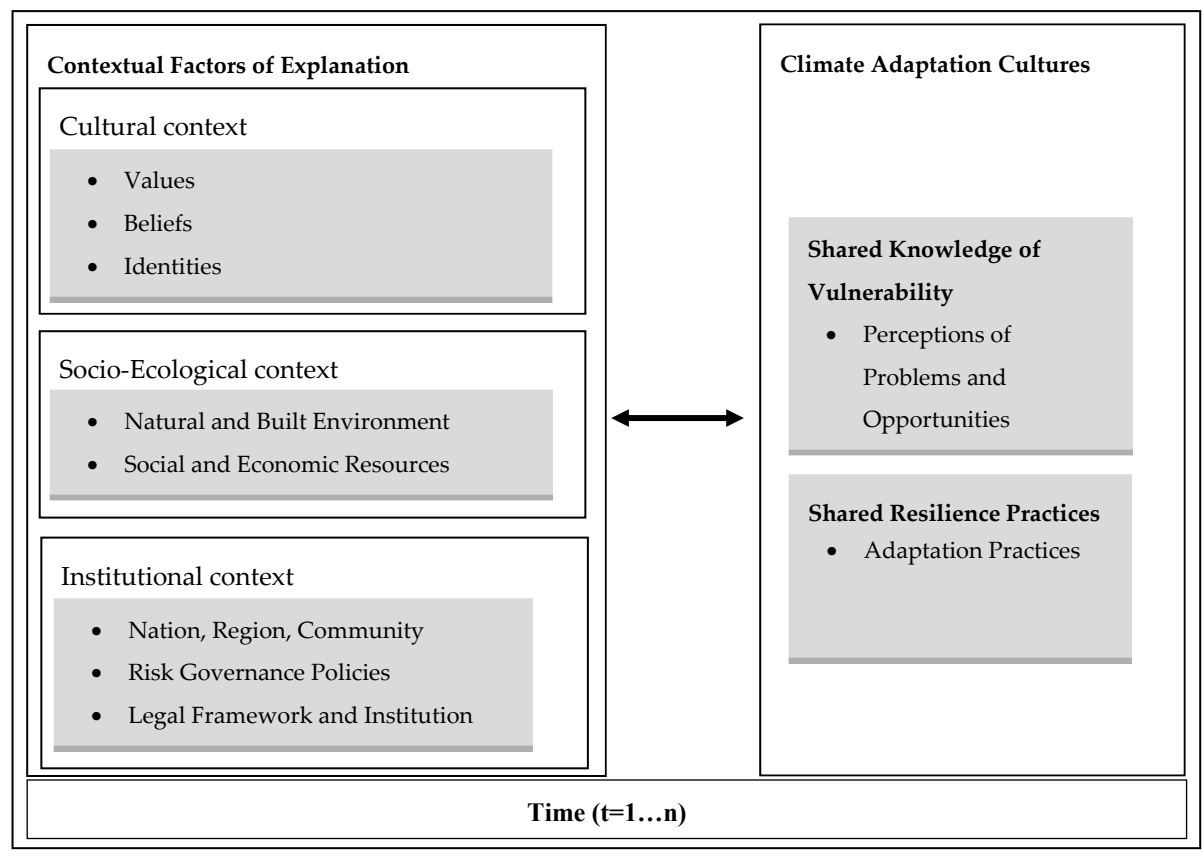

Figure 3. Proposed explanatory framework of climate adaptation cultures.

Climate-adaptation cultures are defined by the shared knowledge of vulnerability and resilience practices. Shared knowledge of vulnerability is defined by the perception of problems and opportunities related to climate change. Shared knowledge of resilience refers to the different adaptation practices (e.g., living with water vs. fighting against water) [1].

Different perceptions and adaptation practices are explained by combinations of the discussed cultural, socio-ecological, and institutional attributes.

- $\quad$ The cultural context of adaptation refers to the VBI model [1] and shows the differences in orders of knowledge.

- The socio-ecological context includes the natural and built environment, social and economic resources reflecting vulnerability, and resilience constructions via state-and-transition model [2].

- The institutional context implies the policies and governance mechanism of relevant institutions which determine existing planning processes for climate adaptation [2].

The application of this model is seen as an integration of the VBI and state-and-transition approaches, which enables the explanation of climate cultures in global contexts, and may explain the differences that emerge in perceiving and handling disaster risks.

The model should be considered for longitudinal analyses as it allows for exploration of developments connected to specific events in time, for example, pre-/post-flood developments $(t=1 \ldots n$, Figure 3$)$. The dynamics of socio-ecological change can be considered based upon chronological changes.

Different models that have been proposed in risk-management research, for example, the "triple loop learning" method, which focuses on the transformation process of knowledge in given social structures, cultural norms, world views, and other constructs that mediate risk management [58]. 
Again, the "adaptation action framework" was proposed in COP15 (for the Copenhagen Agreement) to strengthen the international activities and commitments dealing with current and future impacts of climate change in developing countries [59], but there are no specific operational guidelines under the framework; therefore this is not suitable for understanding "adaptation culture" in general, as we propose in our "climate adaptation culture" model. Furthermore, our proposed model is different from the "triple loop learning", as our model does not only seek to understand adaptation culture, but also focuses on the "differences and similarities in adaptation culture" between different entities such as countries, communities, or individuals. The proposed model is more operational than the afore-mentioned and can contribute to the adaptation framework.

\section{Conclusions}

Based on the empirical evidence from the VBI model (in the Global North) and State-and-transition model (in the Global South), this paper suggests using combinations of culture-theoretical explanations of risk-related perception and action within ecological and institutional contexts. Sustainable disaster management requires adaptation to local distinctiveness and therefore an integrated approach that covers knowledge, ecology, and intuitions is necessary. This is also needed for global comparison of adaptation cultures, as well as transferability of local knowledge. The empirical evidence presented shows that value orientations, beliefs, and identities influence adaptation cultures in Europe, whereas in Bangladesh the adaptation practices depend on the socio-ecological, institutional, and political constellation, although the concept of values-beliefs-identities was not taken into account in the analysis, and vice versa. It is evident from both studies that all these factors are relevant to understanding local adaptation cultures. A future question will be how those factors contribute to explanation and transferability of adaptation practices in global as well as regional contexts. Therefore, combined empirical research must be undertaken.

Acknowledgments: The research on European coastal areas was conducted under Potsdam Research Cluster for Georisk, Analysis, Environmental Change and Sustainability (PROGRESS) funded by the Federal Ministry of Education and Research (BMBF), Germany. Research on coastal areas of Bangladesh was conducted under the PhD Fellowship of the second author given by Catholic Academic Exchange Service (KAAD) and Karlsruhe House of Young Scientists (KHYS). This paper is written under the IRS Fellowship Programme (Leibniz Institute for Research on Society and Space) of Bishawjit Mallick.

Author Contributions: Both authors have equally contributed in designing, analyzing, and writing the paper. The European studies are written by Thorsten Heimann and Bangladesh case study is written by Bishawjit Mallick.

Conflicts of Interest: The authors declare no conflict of interest. The founding sponsors had no role in the design of the study; in the collection, analyses, or interpretation of data; in the writing of the manuscript, and in the decision to publish the results.

\section{References}

1. Heimann, T. Klimakulturen und Raum. Umgangsweisen mit Klimawandel an Europäischen Küsten; Springer: Wiesbaden, Germany, 2017.

2. Mallick, B. Der Gesellschaftliche Umgang mit Zunehmender Verwundbarkeit: Eine Analyse der Sozialen Bedingungen fuer Vulnerabilitaetsorientierte Raeumliche Planung in den Kuestenzonen von Bangladesch; Regional Science Research 2014; KIT Scientific Publishing: Karlsruhe, Germany, 2014.

3. Pellow, D.N.; Brehm, H.N. An environmental sociology for the twenty-first century. Ann. Rev. Sociol. 2013, 39, 229-250. [CrossRef]

4. Dunlap, R.E.; van Liere, K.D. The new environmental paradigm. J. Environ. Educ. 2008, 40, 19-28. [CrossRef]

5. Dunlap, R.E.; van Liere, K.D.; Mertig, A.G.; Jones, R.E. Measuring endorsement of the new ecological paradigm: A revised NEP scale. J. Soc. Issues 2000, 56, 425-442. [CrossRef]

6. Catton, W.R.; Dunlap, R.E. Environmental sociology: A new paradigm. Am. Sociol. 1978, 13, 41-49.

7. Stern, N. The Stern Review: The Economics of Climate Change; Cambridge University Press: Cambridge, UK, 2006.

8. Barnett, J.; Adger, W. Climate change, human security and violent conflict. Political Geogr. 2007, 26, 639-655. [CrossRef] 
9. Kelly, P.M.; Adger, W.N. Theory and practices in assessing vulnerability to climate change and facilitating adaptation. Clim. Chang. 2000, 47, 325-352. [CrossRef]

10. Brennan, G. Climate change: A rational choice politics view. Aust. J. Agric. Resour. Econ. 2009, 53, 309-326. [CrossRef]

11. Diekmann, A.; Preisendörfer, P. Umweltsoziologie. Eine Einführung; Rowohlt: Reinek bei Hamburg, Germany, 2001.

12. Ostrom, E. A general framework for analyzing sustainability of social-ecological systems. Science 2009, 325, 419-422. [CrossRef] [PubMed]

13. Turner, B.L.; Kasperson, R.E.; Matson, P.A.; McCarthy, J.J.; Corell, R.W.; Christensen, L.; Eckley, N.; Kasperson, J.X.; Luers, A.; Martello, M.L.; et al. A framework for vulnerability analysis in sustainability science. Proc. Natl. Acad. Sci. USA 2003, 100, 8074-8079. [CrossRef] [PubMed]

14. Quinn, N.; Holland, D. Culture and cognition. In Dies: Cultural Models in Language and Thought; Cambridge University Press: Cambridge, UK, 1987; pp. 3-40.

15. Reckwitz, A. Die Transformation der Kulturtheorien; Velbrück: Weilerswist, Germany, 2000.

16. Knoblauch, H. Wissenssoziologie; UVK Verlagsgesellschaft: Konstanz, Germany, 2010.

17. Luckmann, T. Wirklichkeiten: Individuelle konstitution und gesellschaftliche konstruktion. In Hermeneutische Wissenssoziologie. Standpunkte zur Theorie der Interpretation; Hitzler, R., Reichert, J., Schröer, N., Eds.; UVK Verlagsgesellschaft: Konstanz, Germany, 1999; pp. 17-28.

18. Foucault, M. Die Ordnung des Diskurses; Fischer: Frankfurt am Main, Germany, 2003.

19. Keller, R.; Knoblauch, H.; Reichertz, J. Kommunikativer Konstruktivismus. Theoretische und Empirische Arbeiten zu Einem Neuen Wissenssoziologischen Ansatz; Springer: Wiesbaden, Germany, 2013.

20. O'Brien, K.; Wolf, J. A values-based approach to vulnerability and adaptation to climate change. In WIREs Climate Change; John Wiley \& Sons, Inc.: New York, NY, USA, 2010.

21. Adger, W.N.; Barnett, J.; Brown, K.; Marshall, N.; O’Brien, K. Cultural dimensions of climate change impacts and adaptation. Nat. Clim. Chang. 2013, 3, 112-117. [CrossRef]

22. Hajjar, R.; Kozak, R.A. Exploring public perceptions of forest adaptation strategies in western Canada: Implication for policy-makers. For. Policy Econ. 2015, 61, 59-69. [CrossRef]

23. Jopp, R.; Mair, J.; Delacy, T.; Fluker, M. Climate change adaptation: destination management and the green tourist. Tour. Plan. Dev. 2015, 12, 300-320. [CrossRef]

24. Thompson, M. Cultural theory, climate change and clumsiness. Econ. Political Wkly. 2003, 38, 5107-5112.

25. Adger, W.N.; Barnett, J.; Chapin, F.S., III; Ellemor, H. This must be the place: Underrepresentation of identity and meaning in climate change decision-making. Glob. Environ. Politics 2011, 11, 1-25. [CrossRef]

26. Devine-Wright, P. Think global, act local? The relevance of place attachments and place identities in a climate changed world. Glob. Environ. Chang. 2013, 23, 61-69. [CrossRef]

27. Kluckhohn, C. Values and value-orientations in the theory of action. In Towards a General Theory of Action; Parsons, T., Shils, E., Eds.; Harvard University Press: Cambridge, MA, USA, 1967; pp. 388-433.

28. Heath, Y.; Giffort, R. Free-market ideology and environmental degradation: the case of belief in global climate change. Environ. Behav. 2006, 38, 48-71. [CrossRef]

29. Schwartz, S.H. Universals in the content and structure of values: Theoretical advances and empirical tests in 20 countries. Adv. Exp. Soc. Psychol. 1992, 25, 1-65.

30. O'Brien, K. Do values subjectively define the limits to climate change adaptation? In Adapting to Climate Change: Thresholds, Values, Governance; Adger, N., Lorenzioni, I., O’Brien, K., Eds.; Cambridge University Press: Cambridge, UK, 2009; pp. 164-181.

31. Inglehart, R. Mapping global values. Comp. Sociol. 2006, 5, 115-136. [CrossRef]

32. Kahan, D.M.; Jenkins-Smith, H.; Braman, D. Cultural cognition of scientific consensus. J. Risk Res. 2010, 14, 147-174. [CrossRef]

33. Price, J.C.; Walker, I.A.; Boschetti, F. Measuring cultural values and belief about environment to identify their role in climate change responses. J. Environ. Psychol. 2014, 37, 8-20. [CrossRef]

34. Douglas, M.; Wildavsky, A. Risk and Culture: An Essay on the Selection of Technological and Environmental Dangers; University of California Press: Berkley, CA, USA; Los Angeles, CA, USA; London, UK, 1982.

35. Dietz, T.; Fitzgerald, A.; Shwom, R. Environmental values. Annu. Rev. Environ. Resour. 2005, 30, $335-372$. [CrossRef] 
36. McNeeley, S.M.; Lazrus, H. The cultural theory of risk for climate change adaptation. Weather Clim. Soc. 2014, 6, 506-519. [CrossRef]

37. Deuble, M.P.; de Dear, R.J. Green occupants for green buildings: The missing link? Build. Environ. 2012, 56, 21-27. [CrossRef]

38. Heyd, T.; Brooks, N. Exploring cultural dimensions of adaptation to climate change. In Adapting to Climate Change: Thresholds, Values, Governance; Adger, N., Lorenzioni, I., O’Brien, K., Eds.; Cambridge University Press: Cambridge, UK, 2009; pp. 269-282.

39. Scannell, L.; Gifford, R. Personally relevant climate change: The role of place attachment and local versus global message framing in engagement. Environ. Behav. 2013, 45, 60-85. [CrossRef]

40. Feitelson, E. Sharing the globe: The role of attachment to place. Glob. Environ. Chang. 1991, 1, $396-406$. [CrossRef]

41. Van Koningsveld, D.M.; Mulder, J.P.M.; Stive, M.J.F.; Vandervalk, L.; Vanderweck, A.W. Living with sea-level rise and climate change: A case study of the Netherlands. J. Coast. Res. 2008, 24, 367-379. [CrossRef]

42. Deltacommissie. Working Together with Water. A Living Land Builds for Its Future. Findings of the Deltacommissie; Hollandia Printing: Alkmaar, The Netherlands, 2008; Available online: http:/ /www.deltacommissie.com/ doc/deltareport_full.pdf (accessed on 15 May 2012).

43. Islam, T.; Atkins, P. Indigenous floating cultivation: A sustainable agricultural practice in the wetlands of Bangladesh. Dev. Pract. 2007, 17, 37-41. [CrossRef]

44. Adger, W. Vulnerability. Glob. Environ. Chang. 2006, 16, 268-281. [CrossRef]

45. Adger, W.N.; Hughes, T.P.; Folke, C.; Carpenter, S.R.; Rockström, J. Social-ecological resilience to coastal disasters. Science 2005, 309, 1036-1039. [CrossRef] [PubMed]

46. DFID (Department for International Development). Defining Disaster Resilience: A DFID Approach Paper; Department for International Development: London, UK, 2011. Available online: http://www.dfid.gov. uk/Documents/publications1/Defining-Disaster-Resilience-DFID-Approach-Paper.pdf (accessed on 12 January 2012).

47. Cutter, S.L.; Barnes, L.; Berry, M.; Burton, C.; Evans, E.; Tate, E.; Webb, J. A placebased model for understanding community resilience to natural disasters. Glob. Environ. Chang. 2008, 18, 598-606. [CrossRef]

48. Forgette, R.; Boening, M.V. Assessing Community Socio-Economic Resilience to Natural Disasters; SERP Research Report; The University of Mississippi: Oxford, MS, USA, 2010. Available online: http://www.olemiss.edu/ depts/economics/serri/serpfactsheet.pdf (accessed on 25 March 2012).

49. Westoby, M.; Walker, B.; Noy-Meir, I. Opportunistic management for rangelands not at equilibrium. J. Range Manang. 1989, 42, 266-274.

50. Stringham, T.K.; Krueger, W.C.; Shaver, P.L. State and transition modeling: An ecological process approach. J. Range Manag. 2003, 56, 106-113. [CrossRef]

51. Brouwer, R.; Akter, S.; Brander, L.; Haque, E. Socio-economic vulnerability and adaptation to environmental risk: A case study of climate change and flooding in Bangladesh. Risk Anal. 2007, 27, 313-326. [CrossRef] [PubMed]

52. Akter, S.; Mallick, B. The poverty-vulnerability-resilience nexus: Evidence from Bangladesh. Ecol. Econ. 2013, 96, 114-124. [CrossRef]

53. Mallick, B.; Rahaman, K.R.; Vogt, J. Coastal livelihood and physical infrastructure in Bangladesh after cyclone Aila. Mitig. Adapt. Strateg. Glob. Chang. 2011, 16, 629-648. [CrossRef]

54. Mallick, B. Cyclone shelters and their locational suitability: An empirical analysis from coastal Bangladesh. Disasters 2014, 38, 654-671. [CrossRef] [PubMed]

55. Mallick, B.; Vogt, J. Social supremacy and its role in local level disaster mitigation planning in Bangladesh. Disaster Prev. Manag. 2011, 20, 543-556. [CrossRef]

56. Mallick, B. Cyclone-induced migration in southwest coastal Bangladesh. ASIEN 2014, 130, 60-68.

57. Mallick, B. Necessity of acceptance? Searching for a sustainable community-based disaster mitigation approach-The example of a coastal city in Bangladesh. In Proceedings of the 2011 Solutions to Coastal Disasters Conference, Reston, Virginia; Wallendorf, L.A., Jones, C., Ewing, L., Battalio, B., Eds.; American Society of Civil Engineers (ASCE) and Coasts, Oceans, Ports and River Institute (COPRI): Reston, VA, USA, 2011; pp. 753-766. 
58. Intergovernmental Panel on Climate Change (IPCC). Managing the Risks of Extreme Events and Disasters to Advance Climate Change Adaptation; A Special Report of Working Groups I and II of the Intergovernmental Panel on Climate Change; Field, C.B., Barros, V., Stocker, T.F., Qin, D., Dokken, D.J., Ebi, K.L., Mastrandrea, M.D., Mach, K.J., Plattner, G.-K., Allen, S.K., et al., Eds.; Cambridge University Press: Cambridge, UK; New York, NY, USA, 2012.

59. UNFCC. Climate Action Network International, Submission to UNFCC Ad Hoc Working Group on Long-Term Cooperative Action Regarding an Adaptation Action Framework, COP15, Copenhagen. Available online: http://unfccc.int/resource/docs/2009/smsn/ngo/128.pdf (accessed on 22 November 2016).

(C) 2016 by the authors; licensee MDPI, Basel, Switzerland. This article is an open access article distributed under the terms and conditions of the Creative Commons Attribution (CC-BY) license (http:/ / creativecommons.org/licenses/by/4.0/). 